\title{
Electrochemical Determination of Trifluralin Herbicide Using Silver Solid Amalgam Electrode: Application in Fresh Food Samples
}

\author{
Danielle Gonçalves Filho ${ }^{a}$ and Djenaine de Souza ${ }^{\circledR * a}$ \\ ${ }^{a}$ Laboratório de Eletroanalítica Aplicada a Biotecnologia e Engenharia de Alimentos (LEABE), \\ Rede Multidisciplinar de Pesquisa, Ciência e Tecnologia (RMPCT), Instituto de Química, \\ Universidade Federal de Uberlândia (UFU), Rua Major Jerônimo, 566, \\ 38700-002 Patos de Minas-MG, Brazil
}

\begin{abstract}
This paper reports the use of polished silver solid amalgam electrode (p-AgSAE) allied to square wave voltammetry (SWV) in the development of a simple, sensitive, fast and green electroanalytical methodology for the trifluralin herbicide determination in fresh food samples. The experimental (supporting electrolyte and potential and time accumulation) and voltammetric (pulse frequency, pulse amplitude and scan increment potential) parameters were previously optimized, which were employed in the construction of analytical curves. Therefore, these curves have enabled the calculation of analytical parameters (linearity range, equation of the analytical curves, coefficients of determination, limits of detection and quantification, recovery efficiency, and relative standard deviations for intraday and interday experiments) and they indicated that the use of the p-AgSAE is suitable for determining any contamination by trifluralin. So, the proposed methodology had to minimize the toxic residues due to the use of liquid mercury or the adsorbed products from the redox reaction that promotes passivation in the other solid surfaces. Furthermore, the optimized methodology was used to trifluralin determination in eggplant, carrot, tomato, grape juice and orange juice, and the results indicated that the proposed methodology presented high robustness, stability and sensitivity, good reproducibility, and hence it is applicable for complex samples.
\end{abstract}

Keywords: trifluralin, electrochemical behavior, fresh food samples, polished silver solid amalgam electrode, square wave voltammetry

\section{Introduction}

In the last years, governmental and health agencies of all world created informative programs, which demonstrate the importance in the consumption of fruits and/or vegetables or minimally processed foods in order to minimize the number of obesity cases and some diseases associated to the consumption of highly processed foods. Hence, organic foods have gained prominence because they are produced without the use of pesticides, while the traditional cultivation employs pesticides that can contaminate fruits, vegetables, water, and soil. The consumption of contaminated fresh food is very dangerous because the ingestion of pesticides can present potential endocrine disrupters, carcinogenic, mutagenic and other disorders. ${ }^{1-3}$

The trifluralin (2,6-dinitro- $N, N$-dipropyl4-trifluoromethylaniline) is one of the pesticides used in fresh foods production, as known as dinitroaniline. ${ }^{4-6}$ Its

*e-mail: djenaine@gmail.com,djenaine@ufu.br chemical structure is presented in Figure 1, and it can be observed the presence of nitro groups, that have intense reactivity in the environment and agricultural products. Thus, these groups can produce intermediary compounds, such as nitroxyl anion radical, nitroso, hydroxylamine and amine, which have a cytotoxic effect on human, protozoal and bacterial cells. ${ }^{7,8}$ Therefore, it is especially important the development of fast, cheap, sensitive and selective techniques for detection of pesticide in fresh food samples.<smiles>CCCN(CCC)c1c([N+](=O)[O-])cc(C(F)(F)F)cc1[N+](=O)[O-]</smiles>

Figure 1. Structural formula of trifluralin herbicide. 
Their determination is commonly performed employing high-performance liquid chromatographic coupled to ultraviolet/visible detector with the use of methanol, which is a highly toxic organic solvent. Moreover, this chromatography analysis requires preliminary samples preparation steps employing solid-phase extraction (SPE) cartridges..$^{9-11}$ While, the use of gas chromatography coupled to nitrogen-phosphorus detector implies in the use of several stages of extraction that demands more reagents, and consequently, it has high costs and longer time of the analyzes. $^{12}$

Some reports had presented the use of electroanalytical techniques in the trifluralin analysis. Gajdár et al..$^{13}$ used antimony film deposited on glassy carbon electrode allied to differential pulse voltammetry technique for the trifluralin determination in river water samples. These samples were pretreated by SPE, which resulted in a methodology more complex, expensive, and longer analysis time. Wen et al. ${ }^{14}$ modified the glassy carbon electrode with a uniform coating of the multi-wall carbon nanotubes and di-hexadecyl hydrogen phosphate for the analysis of trifluralin in soil samples. However, this electrode modification was very complex, time-consuming and the surface needed to be renewed in each experiment, impairing the reproducibility in the trifluralin analytical signal.

Kotouček and Opravilová ${ }^{15}$ employed hanging mercury drop electrode (HMDE) allied to classical fast scan differential pulse voltammetry in the electrochemical behavior study and electroanalytical determination of trifluralin in soil samples. Nonetheless, this methodology promoted a considerable generation of toxic wastes, due to the employment of mercury and toxic organic solvents. Recently, Ferro et al. ${ }^{16}$ used glassy carbon electrode (GCE) allied to square wave voltammetry technique and sodium dodecylsulfate salt (SDS) for trifluralin determination in tap water, fruit juices and vegetable extracts samples. However, trifluralin is highly adsorptive in GCE surface and their cleaning is overly complex and time-consuming.

Based on the above statements, this work aimed the development an electroanalytical methodology for the determination of the trifluralin in fresh foods (carrot, eggplant, grape juice, orange juice and tomato) using a polished silver solid amalgam electrode (p-AgSAE). As p-AgSAE has most of the properties of the HMDE, but without the generation of waste toxic, it is considerate as a nontoxic electrode. Furthermore, this electrode presents an easy-to-prepare, low-cost and suitable reproducibility in their surface. Square wave voltammetry (SWV) is a fast and sensitive voltammetric pulse technique that results in very low limit of detection when compared to traditional methods of analysis, chromatography and spectrophotometry. ${ }^{17-24}$

\section{Experimental}

Instrumentation

A potentiostat model $\mu$ Autolab from Metrohm EcoChemie coupled to Nova 1.11 software was used in all voltammetric experiments. In the preparation of all solutions was employed an analytical Shimadzu balance model AUY 220 and $\mathrm{pH}$ meter from Tecnopon, model mPA 210 equipped with a $3.00 \mathrm{~mol} \mathrm{~L}^{-1} \mathrm{Ag} / \mathrm{AgCl} / \mathrm{KCl}$-glass electrode to measure mass and to adjust $\mathrm{pH}$, respectively. A centrifuge from Centribio model 80-2B was employed in fresh food samples preparations. All solutions used were prepared using deionized water through a Gehaka model OS50 LX with reverse osmosis water purifier system.

\section{Solutions}

The trifluralin standard was kindly supplied by Bayer (Paulínia, Brazil) with $99.50 \%$ of purity, that was used without purification steps. The stock solution of trifluralin was prepared using acetonitrile as the solvent in a concentration of $1.00 \times 10^{-3} \mathrm{~mol} \mathrm{~L}^{-1}$, and posteriorly, it was realized a dilution for $1.00 \times 10^{-4} \mathrm{~mol} \mathrm{~L}^{-1}$, which was used in the analyses. Both solutions were maintained in a dark flask and in the refrigerator to prevent the degradation process.

The $0.04 \mathrm{~mol} \mathrm{~L}^{-1}$ Britton-Robinson (BR) buffer was prepared with the adequated combination of three different acids: phosphoric acid, acetic acid and boric acid, which present six different $\mathrm{p} K_{\mathrm{a}}$ and a wide $\mathrm{pH}$ range to prepare buffer solutions, from 2.0 to $12.0 .^{25}$ The $\mathrm{pH}$ adjustment of the buffer was made using $1.00 \mathrm{~mol} \mathrm{~L}^{-1}$ sodium hydroxide solution $(\mathrm{NaOH})$. These reactants were purchased from Vetec (Paulínia, Brazil) with analytical purity and were employed without early purification steps.

\section{Electrochemical cell}

The electrochemical cell was composed by electrical conductors (working, auxiliary and reference electrodes) and an ionic conductor (BR buffer with $\mathrm{pH}$ values previously determined). A platinum wire was used as an auxiliary electrode and an $\mathrm{Ag} / \mathrm{AgCl}$ in $\mathrm{KCl} 3.00 \mathrm{~mol} \mathrm{~L}^{-1}$ was used as a reference electrode.

The working electrode used was a homemade p-AgSAE prepared from mechanical amalgamation process using the ratio of $30 / 70(\mathrm{~m} / \mathrm{m})$ silver (particle size: $5-9 \mu \mathrm{m}$, purity: 99.9\% from Sigma-Aldrich, São Paulo, Brazil) 
and mercury mass (purity: 99.99\% from Synth, São Paulo, Brazil), respectively, according to the previously published methodology. ${ }^{26}$ In this proportion, the electrode presents a solid and compact surface, and it does not have mercury or oxides from mercury and silver. Besides this, the homemade p-AgSAE presented similar electrochemical properties of HMDE and additional properties such as ease in renewing the electrode surface by electrochemical treatment, low resistance to the charge transfer, good reproducibility and it does not generate mercury waste during the electrochemical analysis. For this, p-AgSAE was considered as a nontoxic electrode. ${ }^{17-26}$

Before the start of the analysis, the electrode was polished in fine sandpaper (3M, Ribeirão Preto, Brazil) and electrochemically activated using $0.20 \mathrm{~mol} \mathrm{~L}^{-1} \mathrm{KCl}$ solution (Synth, São Paulo, Brazil, with analytical purity) and cyclic voltammetry experiments with scan potential from 0.00 to $-2.20 \mathrm{~V}$ for 500 cycles and a scan rate of $500 \mathrm{mV} \mathrm{s}^{-1}$. This pre-treatment was necessary to reduce electron transfer resistance by removal of oxides in the electrode surface and was preliminarily realized in the voltammetric experiments after $1 \mathrm{~h}$ without employing the working electrode. Moreover, between each voltammetric experiments was applied a fixed potential of $-2.20 \mathrm{~V}$ for $30 \mathrm{~s}$, in the same working solution, which promotes a complete renovation of the p-AgSAE surface by removal of adsorbed products from redox reaction.

\section{Experimental and voltammetric optimization}

Preliminary analyses were performed using BR buffer as supporting electrolyte in a $\mathrm{pH}$ range of 2.0 to 12.0 and the voltammetric responses were obtained by SWV technique. In an electrochemical cell containing $10 \mathrm{~mL}$ of electrolyte, three successive additions of the standard solution of trifluralin were made, obtaining the following concentrations in the electrochemical cell: $4.76 \times 10^{-5}$, $9.09 \times 10^{-5}$ and $1.30 \times 10^{-4} \mathrm{~mol} \mathrm{~L}^{-1}$ of trifluralin. Previously the voltammetric experiments, the cell was deoxygenated by insertion of high purity nitrogen gas, from White Martins (Uberlândia, Brazil) into the solution for $10 \mathrm{~min}$.

After each addition of trifluralin standard solution, the potential range was scanned from 0.00 to $-1.50 \mathrm{~V}$ using $100 \mathrm{~s}^{-1}$ as the frequency of pulse potential $(f),-50 \mathrm{mV}$ as pulse amplitude (a) and $-2 \mathrm{mV}$ as scan potential increment $\left(\Delta \mathrm{E}_{\mathrm{s}}\right)$. All voltammetric responses were evaluated considering the position, height, and half-height width of each voltammetric peak to obtain a suitable sensitivity and selectivity in the proposed methodology.

Since the redox behavior of nitro group indicates the possibility in the use of accumulation step, whose resultant species are subsequently reduced producing a suitable increase in voltammetric signals in this work, the influence of the potential and time of the accumulation of the trifluralin under p-AgSAE in the voltammetric responses was previously studied. Hence, the potential accumulation was changed to values before, at the top and after the first reduction peak, during times from 0 to $60 \mathrm{~s}$, and posteriorly the SWV responses were evaluated.

After experimental optimization, the SWV parameters were properly optimized since their values exert a deep influence on the intensities of the voltammetric signals. The $f$ values were changed from 10 to $300 \mathrm{~s}^{-1}$, the a from -5 to $-50 \mathrm{mV}$ and $\Delta \mathrm{E}_{\mathrm{s}}$ from -2 to $-10 \mathrm{mV}$. These parameters were evaluated considering the position, height, and half-height width of the obtained peaks.

\section{Analytical parameters}

With the experimental and voltammetric optimization, analytical curves were obtained in the pure electrolyte by the standard addition method. The standard deviation $\left(\mathrm{S}_{\mathrm{b}}\right)$ of the peak current values were measured at redox potential of trifluralin, considering twenty voltammograms obtained in the pure electrolyte, and the slope of the straight line (s) of the analytical curves were used in the calculous of the limits of detection and quantification (LOD and LOQ, respectively), according to guidelines recommended by International Union of Pure and Applied Chemistry (IUPAC). ${ }^{27}$

The accuracy of the proposed methodology was evaluated using recovery experiments, which were made by the addition of a known amount of trifluralin followed by trifluralin standard solution additions to the supporting electrolytes. For each addition, the voltammetric responses were evaluated producing recovery curves, that are performed in triplicate. The recovery efficiencies (\%R) were calculated considering the value of the percentage relationships between [trifluralin $]_{\text {added }}$ and [trifluralin $]_{\text {found }}$, refering to the concentration obtained by extrapolating the recovery curves of the corresponding artificially spiked samples.

The precision of the proposed methodology was evaluated using reproducibility and repeatability experiments. Reproducibility was evaluated using five different standard solutions of trifluralin in five different days (interday precision). Repeatability (intraday precision) was performed using ten successive measurements of a standard solution of trifluralin and analyzing the resultant signals. The relative standard deviations (RSD) were calculated for the reproducibility and repeatability measures, which used the percentage relationships between 
the standard deviation and the mean of the obtained peakcurrent. $^{28}$

\section{Fresh foods applications}

Fresh fruits and vegetables, such as carrot, eggplant, grape juice, orange juice and tomato were obtained from local fairs in the city of Patos de Minas, Minas Gerais, Brazil, to attest the efficiency of the proposed methodology. The authors stated that there were no pesticide residues in the samples. For this, these samples were employed to evaluate the influence of their composition in the analytical responses. Therefore, recovery curves were constructed in triplicate and it was used the same methodology effectuated in the pure electrolyte.

The grape and orange juices samples were homogenized, filtered and used without any other additional treatments. Eggplant, tomato and carrot samples were ground using a mixer, and $5.0 \mathrm{~g}$ of each sample was added to a bottle containing $10 \mathrm{~mL}$ of acetone and was placed during $5 \mathrm{~min}$ on a shaker, and posteriorly it was centrifuged for $5 \mathrm{~min}$ at $3000 \mathrm{rpm}$, according to previously published method..$^{29}$ The supernatant was collected in a tube covered with aluminium foil, which was added to avoid degradation of trifluralin by sunlight. $1.00 \mathrm{~mL}$ of each sample was used for the construction of recovery curves, which was made with previously fortification (artificially contaminated) and without fortification, by standard addition method in the cell following the construction of recovery curves, similar to performed in electrolyte. These recovery curves were performed in triplicate, and the average recovery values were calculated.

\section{Results and Discussion}

\section{Experimental optimization}

The $\mathrm{pH}$ of the supporting electrolyte can significantly affect the voltammetric responses of organic molecules, mainly nitro pesticides. For this, the $\mathrm{pH}$ was previously evaluated using BR buffer with values from 2.0 to 12.0 and SWV experiments, where it was possible to observe that the peak potential $\left(\mathrm{E}_{\mathrm{p}}\right)$ of trifluralin moved to more cathodic values with the increase of $\mathrm{pH}$. Additionally, the number of peaks, the position, height, and width of the peaks also were strongly affected by the $\mathrm{pH}$ value, as shown in Figures 2a and $2 \mathrm{~b}$. In a strongly acid medium, the trifluralin presents two reduction peaks. However, with the increase of $\mathrm{pH}$ new
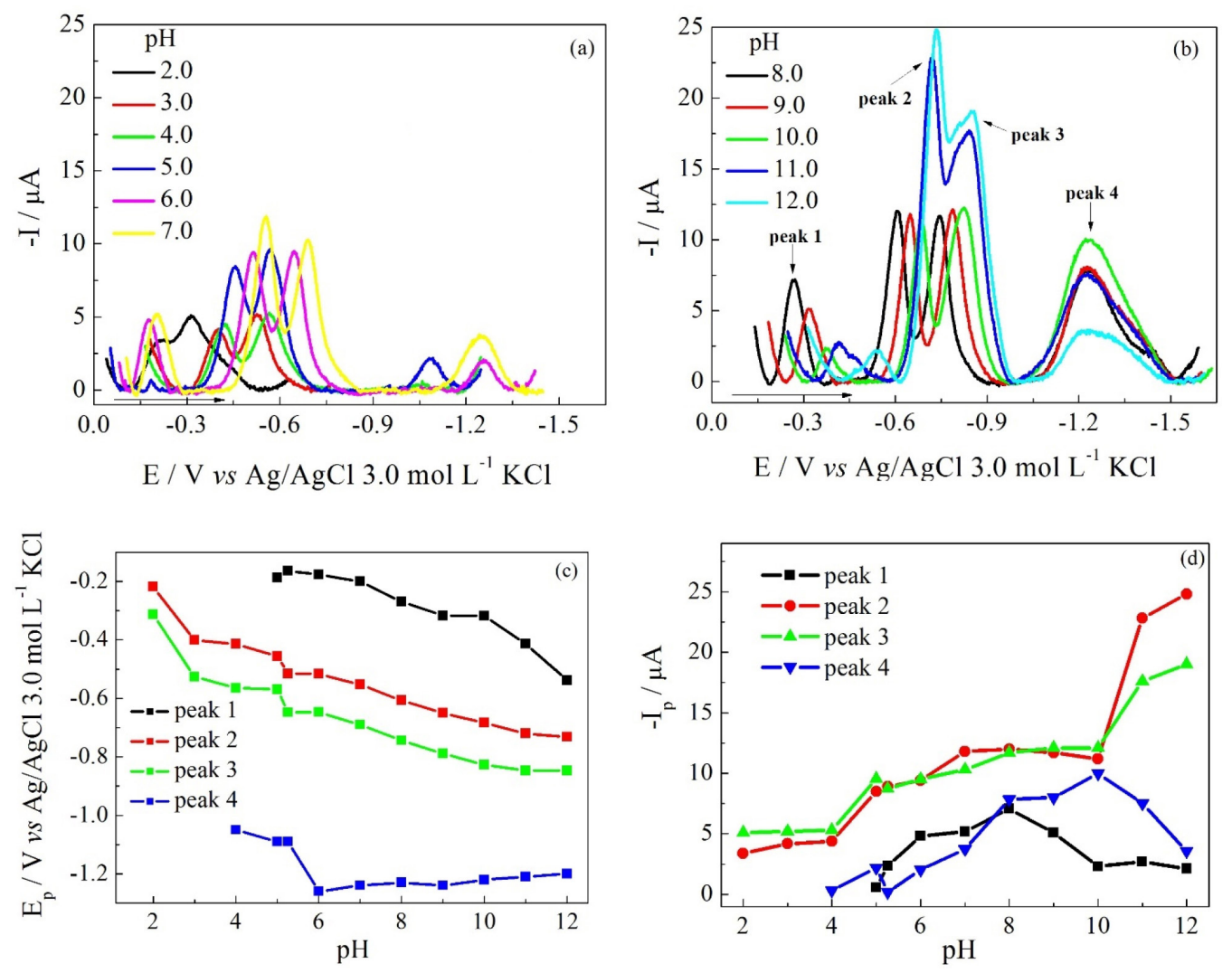

Figure 2. (a) and (b) square wave voltammograms for $1.30 \times 10^{-5} \mathrm{~mol} \mathrm{~L}^{-1}$ trifluralin on the p-AgSAE using $0.04 \mathrm{~mol} \mathrm{~L}^{-1} \mathrm{BR}$ buffer solution in different $\mathrm{pH}$ values and $f=100 \mathrm{~s}^{-1}, \mathrm{a}=-50 \mathrm{mV}$ and $\Delta \mathrm{E}_{\mathrm{s}}=-2 \mathrm{mV}$. (c) Relationships between the $\mathrm{pH}$ values and the peak potentials from voltammograms in (a) and (b). (d) Relationships between the $\mathrm{pH}$ values and the peak currents from voltammograms in (a) and (b). 
reduction peaks arise, so, in the basic medium was observed four well-defined voltammetric peaks, over the potential range evaluated, from 0.00 to $-1.50 \mathrm{~V}$.

The analysis of Figures $2 \mathrm{a}$ and $2 \mathrm{~b}$ indicated that in the peaks 1, 2 and 3 the $E_{p}$ shifted towards more negative values when $\mathrm{pH}$ increased, typical of redox reactions in which protonation equilibrium participates in the redox reactions. The relationships between $\mathrm{E}_{\mathrm{p}}$ and $\mathrm{pH}$ values for each voltammetric peak as shown in Figure 2c are described by equations bellow, where $\mathrm{E}_{\mathrm{p}}$ and the intercept are in Volts:

$$
\begin{aligned}
& \mathrm{E}_{\mathrm{p} 1}=0.182-0.056 \mathrm{pH} \\
& \mathrm{E}_{\mathrm{p} 2}=-0.277-0.040 \mathrm{pH} \\
& \mathrm{E}_{\mathrm{p} 3}=-0.412-0.040 \mathrm{pH} \\
& \mathrm{E}_{\mathrm{p} 4}=-1.309-0.009 \mathrm{pH}
\end{aligned}
$$

Equation 1 represents a straight line with a slope that is very close to the theoretical value predicted by the Nernst equation for an electrochemical reaction involving the same number of protons and electrons $\left(0.0592 \mathrm{~V} / \mathrm{pH}\right.$ at $\left.25^{\circ} \mathrm{C}\right)$ for peak 1. Equations 2 and 3 present inclinations values like observed in redox reactions that relate the transfers of one proton and two electrons. Thus, considering peak 4, the inclination value (equation 4) indicated that the protonation equilibrium presented no relevance in the electrons transfer reaction.

The relationships between peak current $\left(\mathrm{I}_{\mathrm{p}}\right)$ and $\mathrm{pH}$ are shown in Figure 2d, which indicated that the higher intensities of peaks were obtained at more basic $\mathrm{pH}$ values. However, at $\mathrm{pH}$ more than 8.0 it was observed strong adsorption of reagent and/or product reaction on the p-AgSAE surface, that had resulted in the voltammetric signal reduction and poor repeatability. So, the $\mathrm{pH}$ chosen for the development of the methodology was 7.0, due to voltammetric signal with suitable intensity (intense peak height) and resolution (small peak width). Moreover, the samples analyzed were food, which in turn have the
$\mathrm{pH}$ close to neutral. So, in $\mathrm{pH} 7.0$ had four well-defined voltammetric peaks, at $-0.206,-0.563,-0.689$ and $-1.244 \mathrm{~V}$ called as peaks $1,2,3$ and 4 , respectively.

Influence of time and potential of the accumulation

According to previously published works involving nitro compounds, ${ }^{17-24}$ we can propose that at $\mathrm{pH}$ values higher than 6.0, peak 1 corresponds to a step of the reaction, that occurred the formation of an intermediate radical anion from the preliminary nitro-groups reduction present in the trifluralin, which was consecutively reduced resulting in the peaks 2 and 3. Thus, the product reaction generated around potential values at peak 1 was the reactant in the next steps of the reaction represented by peaks 2 and 3. Hence, a study about the influence of the potential $\left(\mathrm{E}_{\mathrm{acc}}\right)$ and time $\left(\mathrm{t}_{\mathrm{acc}}\right)$ of the accumulation of the anion radical from trifluralin reaction in the $I_{p}$ and $E_{p}$ values were evaluated using $E_{\text {acc }}$ at $-0.143,-0.206$ and $-0.284 \mathrm{~V}$, that correspond to potential before, at the top and after the peak 1 , during times $30 \mathrm{~s}$.

Besides this, the resultant voltammograms shown in Figure 3 practically did not show a difference in the signal intensity considering all $\mathrm{E}_{\mathrm{acc}}$. However, when the signal was compared to voltammograms without $\mathrm{E}_{\text {acc }}$ application (open circuit potential condition), it could be observed an intense increase in $I_{p}$ values for peaks 2 and 3 and a dislodgment in the $\mathrm{E}_{\mathrm{p}}$ to more cathodic values, typical of presence of adsorptive process in $\mathrm{p}-\mathrm{AgSAE}$ surface. This occurs due to applying the $\mathrm{E}_{\text {acc }}$ around peak 1, which became negligible, indicating that all formed product is consumed in the next stage of reduction, peaks 2 and 3. Therefore, it was confirmed by cyclic voltammetry experiments, considering different potential scan rates in successive cycles of the potential scan (data not show).

Additionally, $\mathrm{t}_{\mathrm{acc}}$ was applied from 0 to $60 \mathrm{~s}$ as shown in Figure 3b. When the voltammetric responses without
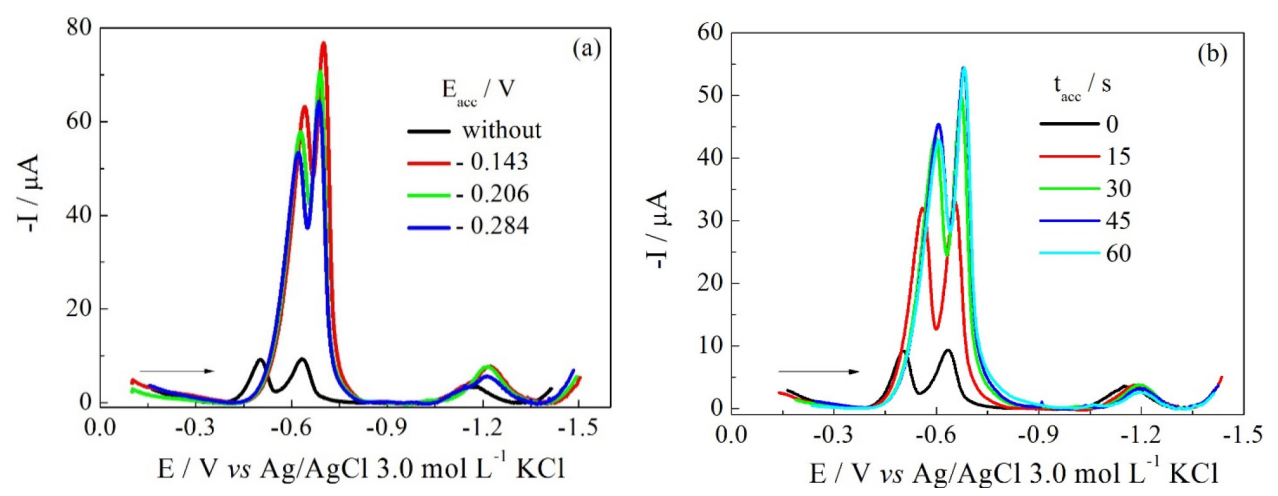

Figure 3. Square wave voltammograms for $9.09 \times 10^{-6} \mathrm{~mol} \mathrm{~L}^{-1}$ trifluralin on the p-AgSAE using $0.04 \mathrm{~mol} \mathrm{~L}^{-1} \mathrm{BR}$ buffer solution $\mathrm{pH} 7.0$ and $f=100 \mathrm{~s}^{-1}$, $\mathrm{a}=-50 \mathrm{mV}$ and $\Delta \mathrm{E}_{\mathrm{s}}=-2 \mathrm{mV}$, where (a) shows the accumulation potential variation, $\mathrm{E}_{\text {acc }}$ and open circuit potential condition (without) and (b) shows the time of accumulation, $\mathrm{t}_{\text {acc }}$ at optimized $\mathrm{E}_{\text {acc }}(-0.143 \mathrm{~V})$. 
potential application were compared with responses applying $-0.143 \mathrm{~V}$ was observed that its $\mathrm{I}_{\mathrm{p}}$ values were tripled until $30 \mathrm{~s}$. Nonetheless, after $30 \mathrm{~s}$ of $\mathrm{E}_{\text {acc }}$ application was observed a negligible increase in the $\mathrm{I}_{\mathrm{p}}$, probably due to the redox products of the first step of the trifluralin reaction practically complete coverage of the p-AgSAE. In this way, the accumulation time chosen was $15 \mathrm{~s}$.

\section{Voltammetric optimization}

$10 \mathrm{~mL}$ BR buffer pH 7.0 plus $9.09 \times 10^{-5} \mathrm{~mol} \mathrm{~L}^{-1}$ of trifluralin, $\mathrm{E}_{\text {acc }}$ of $-0.143 \mathrm{~V}$ during $15 \mathrm{~s}$ were used as experimental parameters in the SWV experiments to evaluate the voltammetric parameters, which permitted the acquisition of the best analytical signal. Thus, each SWV parameter $\left(f\right.$, a and $\left.\Delta \mathrm{E}_{\mathrm{s}}\right)$ was individually evaluated, and the results are described below. The use of $E_{\text {acc }}$ promoted the disappearance of peak 1 , and for this, the voltammetric parameters are evaluated considering only peaks 2 and 3 that present remarkably close $\mathrm{E}_{\mathrm{p}}$ values. The peak 4 presented low intensity in $\mathrm{pH} 7.0$ and unfavorable peak value $\mathrm{E}_{\mathrm{p}}$, hence, it was not used for analytical purposes in this work.

The $\Delta \mathrm{E}_{\mathrm{s}}$ is the voltammetric parameter that together with $f$ indicates the scan rate potential in the voltammetric analysis because influences the analytical sensitivity. So, $\Delta \mathrm{E}_{\mathrm{s}}$ parameter was varied from -2 to $-10 \mathrm{mV}$ and the results showed that the increase of $\Delta \mathrm{E}_{\mathrm{s}}$ promoted a non-linear increase in $I_{p}$ similar to that occurs in redox reactions involving reactants and products adsorbed on the electrode surface. ${ }^{23}$ Besides this, the increase in $\Delta \mathrm{E}_{\mathrm{s}}$ was accompanied by an increase in the width of the voltammetric peak and a dislodgment in $\mathrm{E}_{\mathrm{p}}$ to more cathodic potential values, that promoted a loss in the analytical selectivity. Because the narrower voltammetric peaks are related to more selective analysis, this signal will suffer less interference from other species that may reduce in the similar potential value. For this, $-2 \mathrm{mV}$ was selected as $\Delta \mathrm{E}_{\mathrm{s}}$ parameter in subsequent experiments.

The a parameter is related to the pulse potential height applied, and it can also interfere in the analytical signal. So, a parameter was evaluated from -5 to $-50 \mathrm{mV}$, and the resultants voltammograms showed a linear increase in $\mathrm{I}_{\mathrm{p}}$ until $-25 \mathrm{mV}$, and above this value it was observed a non-linearity. Additionally, both voltammetric peaks shifted to more positive values as long as values were increased, typical to redox processes involving strong adsorption from products and reactants at the electrode surface. ${ }^{30}$ Thus, for analytical applications, a value of $-25 \mathrm{mV}$ was chosen for a parameter.

The $f$ is an important SWV parameter to be evaluated because of the voltammetric responses in $\operatorname{different} f$ values provide information about the kinetics, reversibility of reactions, and evaluate adsorption process of the trifluralin or its products redox reaction on the p-AgSAE. In this work, $f$ was evaluated in a range of 10 to $300 \mathrm{~s}^{-1}$, where it can be observed that the increase in $f$ values promoted an increase in $\mathrm{I}_{\mathrm{p}}$ and the dislodgment in the $\mathrm{E}_{\mathrm{p}}$ values to more negative direction potential, for both peaks 2 and 3 , typical of redox process involving reactant and/or product adsorption as the rate-determining step in the redox mechanism. ${ }^{30}$

Likewise, the analysis of the plot of the $\mathrm{I}_{\mathrm{p}}$ versus $f$ values showed a change in the slopes, that indicated an alteration in the redox process related to changes in the mass transfer process and consequently, in the kinetic behaviors for both voltammetric peaks when the scan rates $\left(f \times \Delta \mathrm{E}_{\mathrm{s}}\right)$ was increased. Besides this, it was possible to observe that the $\mathrm{I}_{\mathrm{p}}$ increased linearly with $f$ values until $100 \mathrm{~s}^{-1}$ without signal distortions, posteriorly value occurs an increase in half-height width. Thus, in further experiments, the value employed to assure the maximum intensity was $100 \mathrm{~s}^{-1}$.

\section{Analytical parameters}

The experimental and voltammetric optimized parameters (BR buffer $\mathrm{pH} 7.0, \Delta \mathrm{E}_{\mathrm{s}}=-2 \mathrm{mV}, \mathrm{a}=-25 \mathrm{mV}$ and $\left.f=100 \mathrm{~s}^{-1}\right)$ were used in the construction of the analytical curve, where it was realized successive additions of trifluralin from $2.50 \times 10^{-7}$ to $1.75 \times 10^{-6} \mathrm{~mol} \mathrm{~L}^{-1}$ in an electrochemical cell and SWV experiments performed in potential range from -0.30 to $-0.80 \mathrm{~V}$. The potential range are related to interval potential of reduction of peaks 2 and 3 , the most suitable redox peaks to analytical purposes.

In Figure 4a can be observed that the increase in the trifluralin concentrations promoted an increase in the $I_{p}$ values, which was accompanied by a dislodgment in $E_{p}$ to more negative values and an increase in half-height width. So, it was constructed 10 analytical curves, and the above-described behavior was observed in all voltammetric results. Then, three analytical curves were used to calculous of the analytical parameters, and the average analytical curve obtained is shown in Figure $4 b$, for peaks 2 and 3.

According to the classification of the solute adsorption isotherm in diluted solutions defined by Giles et al., ${ }^{31}$ the profiles of analytical curves, shown in Figure 4b, demonstrated the predominance of the S-type curves. These curves are related to chemical systems where the activation energy for desorption of the solute depends on the concentration and is reduced by adsorption contributions of a second solute, indicating "cooperative adsorption". In the trifluralin reaction on the $\mathrm{p}-\mathrm{AgSAE}$, the $\mathrm{E}_{\text {acc }}$ promote 

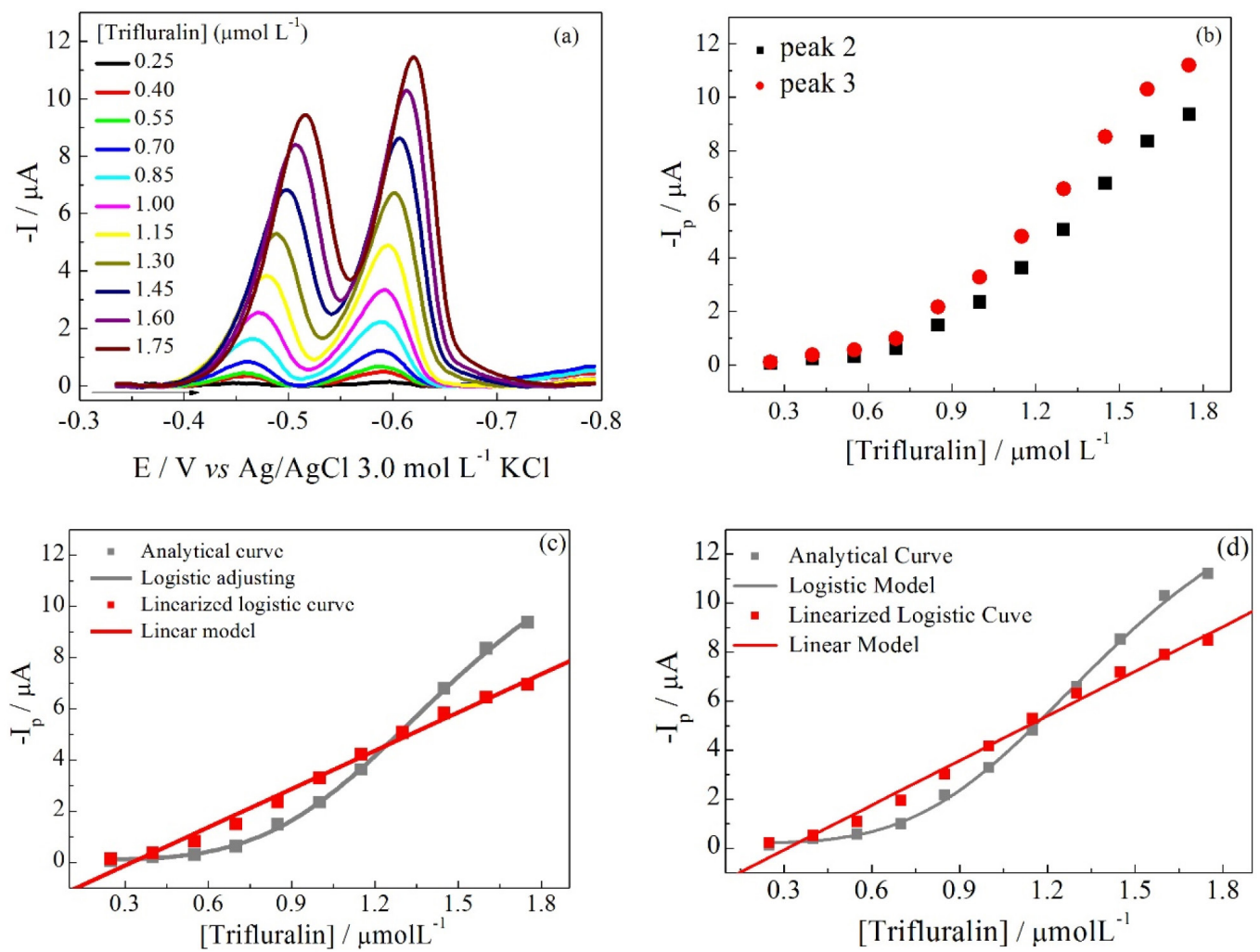

Figure 4. (a) SWV responses obtained using BR buffer $\mathrm{pH} 7.0$, recorded with $f=100 \mathrm{~s}^{-1}, \mathrm{a}=-50 \mathrm{mV}, \Delta \mathrm{E}_{\mathrm{s}}=-2 \mathrm{mV}, \mathrm{E}_{\mathrm{acc}}=-0.143 \mathrm{~V}$ and $\mathrm{t}_{\mathrm{acc}}=15 \mathrm{~s}$ on the p-AgSAE, using concentrations in the range from $2.50 \times 10^{-7}$ to $1.75 \times 10^{-6} \mathrm{~mol} \mathrm{~L}^{-1}$. (b) Averaged currents obtained for three analytical from early SWV responses. (c) Resultant curve from non-linear regression to peak 2. (d) Resultant curve from non-linear regression to peak 3.

a preconcentration of radical anions in $\mathrm{p}-\mathrm{AgSAE}$ surface (adsorption process), which is reduced and generated an adsorbed product, confirmed by a reduction in analytical signals after successive SWV experiments. Besides, the relationships between the S-type profile and chemical structure of trifluralin are indicative that occurs the association of the aromatic ring with an electrode surface perpendicularly to the surface, like observed in planar aromatic molecules. ${ }^{32}$

In this work, no linear relationships between $I_{p}$ and trifluralin concentration were observed. However, the linearization was obtained using logistic function, a nonlinear function that promotes the best fit of the experimental to data that present S-type profile. ${ }^{33-35}$ This way, the adjustment permitted the evaluation and validation of the analytical parameter proposed in this work, as shown in Figures $4 \mathrm{c}$ and $4 \mathrm{~d}$, to peaks 2 and 3 , respectively. The most favorable approach to the linear adjustment is represented by equation equations $5-6$, considering the average of the three analytical curves and both voltammetric peaks, and its respective confidence interval:

$-\mathrm{I}_{\mathrm{p} 2}(\mu \mathrm{A})=-1.631 \times 10^{-6}\left(\mp 3.939 \times 10^{-7}\right)+4.995(\mp 2.371)[$ trifluralin $] \mu \mathrm{mol} \mathrm{L}^{-1}$

$-\mathrm{I}_{\mathrm{p} 3}(\mu \mathrm{A})=-1.889 \times 10^{-6}\left(\mp 5.873 \times 10^{-7}\right)+6.074(\mp 3.594)+[$ trifluralin $] \mu \mathrm{mol} \mathrm{L}^{-1}$
The confidence interval (CI) was calculated to evaluate systematic errors using the equation below:

$\mathrm{CI}=$ value $\mp t_{\mathrm{n}-1}\left(\frac{\mathrm{s}}{\sqrt{\mathrm{n}}}\right)$

where value is the average of the interception or slope of the linearized analytical curves, $t_{\mathrm{n}-1}$ is the tabulated $t$ value, $\mathrm{s}$ is the standard deviation of the parameters and $\mathrm{n}$ is the number of measures. These analyses were also performed at an assurance level of $95 \%$, and the values calculated are presented in equations 5 and 6.

From the linearized analytical curves was calculated the limit of detection (LOD) and limit of quantification (LOQ) for trifluralin reduction on $\mathrm{p}-\mathrm{AgSAE}$, according to the previously optimized parameters, that were calculated employing the criteria presented in the Experimental section. Table 1 shows the parameters obtained, which are the standard deviation $\left(\mathrm{S}_{\mathrm{b}}\right)$ of blank responses, the slope and the intercept from the analytical curves, the degree of linearity between trifluralin concentration and $I_{p}$ values given by the correlation coefficient (r), LOD and LOQ calculated.

The values of the LOD and LOQ for trifluralin on the p-AgSAE were slightly higher than those determined by 
Table 1. Analytical parameters for the determination of trifluralin in BR buffer $\mathrm{pH} 7.0$ on p-AgSAE and their respective comparison with other data reported in specific literature

\begin{tabular}{|c|c|c|c|c|c|}
\hline \multirow{2}{*}{ Parameter } & \multicolumn{2}{|c|}{ This work } & \multirow{2}{*}{ HPLC/UV-Vis ${ }^{11}$} & \multirow{2}{*}{$\mathrm{HMDE}^{15}$} & \multirow{2}{*}{$\mathrm{GCE}^{16}$} \\
\hline & Peak 2 & Peak 3 & & & \\
\hline Concentration range / $\left(\mu \mathrm{mol} \mathrm{L}{ }^{-1}\right)$ & \multicolumn{2}{|c|}{$0.25-1.75$} & $0.20-50.0$ & $0.20-1.18$ & $0.48-32.20$ \\
\hline Intercept $/ \mu \mathrm{A}$ & -1.63 & -1.89 & 0.93 & 1.04 & -0.15 \\
\hline $\mathrm{s} /\left(\mathrm{A} \operatorname{per} \mathrm{mol} \mathrm{L}^{-1}\right)$ & 4.99 & 6.07 & -0.034 & 0.004 & -1.06 \\
\hline $\mathrm{r}$ & 0.994 & 0.995 & 0.998 & 0.999 & 0.999 \\
\hline $\mathrm{S}_{\mathrm{b}} / \mu \mathrm{A}$ & 0.279 & 0.331 & NR & NR & NR \\
\hline $\begin{array}{l}\mathrm{LOD} /\left(\mu \mathrm{mol} \mathrm{L}^{-1}\right) \\
\mathrm{LOD} /\left(\mu \mathrm{g} \mathrm{L}^{-1}\right)\end{array}$ & $\begin{array}{c}4.56 \times 10^{-3} \\
1.53\end{array}$ & $\begin{array}{c}4.16 \times 10^{-3} \\
1.39\end{array}$ & NR & $\begin{array}{c}0.062 \\
0.12\end{array}$ & $\begin{array}{l}0.031 \\
10.39\end{array}$ \\
\hline $\begin{array}{l}\mathrm{LOQ} /\left(\mu \mathrm{mol} \mathrm{L}^{-1}\right) \\
\mathrm{LOQ} /\left(\mu \mathrm{g} \mathrm{L}^{-1}\right)\end{array}$ & $\begin{array}{c}14.6 \times 10^{-3} \\
4.89\end{array}$ & $\begin{array}{c}13.30 \times 10^{-3} \\
4.46\end{array}$ & $\begin{array}{c}4.50 \times 10^{-3} \\
1.51\end{array}$ & NR & $\begin{array}{l}0.104 \\
34.87\end{array}$ \\
\hline Repeatability / \% & 15.97 & 3.86 & $1.10 \mathrm{DW}$ & NR & $3.83 \mathrm{TW}$ \\
\hline Reproducibility / \% & 17.28 & 9.78 & $1.30 \mathrm{DW}$ & 4.50 & $5.06 \mathrm{TW}$ \\
\hline Recovery / \% & $98.92 \mathrm{E}$ & $98.54 \mathrm{E}$ & $99.40 \mathrm{DW}$ & 96.00 SPE-SS & $102.08 \mathrm{TW}$ \\
\hline
\end{tabular}

HPLC/UV-Vis: high-performance liquid chromatographic with ultraviolet/visible detector; HMDE: handing dropping mercury electrode; GCE: glass carbon electrode; r: correlation coefficient; $\mathrm{S}_{\mathrm{b}}$ : standard deviations; s: the slope of the analytical curves; LOD: limit of detection; LOQ: limit of quantification; E: electrolyte; DW: distilled water; SPE-SS: solid-phase extraction in soil samples; TW: solid-phase extraction in tap water; NR: no reported.

HPLC/UV-Vis using SPE steps, which is the common methodology employed to its determination. However, the values of these parameters were much lower when compared to the traditional HMDE and GCE, as indicated in Table 1. Moreover, this work did not employ SPE steps, minimizing the time and costs of the analysis. Additionally, the LOD calculated using p-AgSAE allied to SWV is lower than the maximum permitted levels in different samples by the Environmental Protection Agency (EPA) (i.e., $50.00 \mu \mathrm{g} \mathrm{L}{ }^{-1}$ or $\left.1.49 \times 10^{-7} \mathrm{~mol} \mathrm{~L}^{-1}\right) .^{36}$

The recovery curves were constructed in triplicate and the results obtained are shown in Table 1, the pure electrolyte was composed of $0.04 \mathrm{~mol} \mathrm{~L}^{-1} \mathrm{BR}$ buffer $\mathrm{pH} 7.0$ solution and it was spiked with $5.50 \times 10^{-7} \mathrm{~mol} \mathrm{~L}^{-1}$ of trifluralin. Posteriorly, it was made the addition of the standard solutions to observe and quantify the amounts of trifluralin added. Likewise analytical curves, the logistic function was used to obtain linearization from relationships between the $I_{p}$ and trifluralin concentration added.

After linearization, recovery efficiencies were calculated using the relationship between the observed experimental concentration value and the expected concentration value, as shown in Experimental section. The recovery values calculated were 98.92 and $98.54 \%$, for peaks 2 and 3, respectively. Thus, according to the International Conference on Harmonization (ICH), these values are very satisfactory for analytical methodologies, for which recovery efficiencies from 70 to $130 \%$ are accepted as an indication of the suitable analytical methodologies. ${ }^{37}$

The precision and accuracy of the p-AgSAE used in the analytical determination of trifluralin were also evaluated.
The precision was calculated from reproducibility experiments, that was made in five different measurements on different days, with a standard solution containing $5.50 \times 10^{-7} \mathrm{~mol} \mathrm{~L}^{-1}$ trifluralin using the methodology shown earlier, where the calculated RSD was 17.28 and $9.78 \%$ for peaks 2 and 3, respectively. The accuracy of the measurements was also evaluated from ten repetitive determinations (repeatability) of the same standard solution containing $5.50 \times 10^{-7} \mathrm{~mol} \mathrm{~L}^{-1}$ of trifluralin, and so, the RSD obtained was 15.97 and $3.86 \%$ for peaks 2 and 3, respectively.

The RSD values to repeatability and reproducibility experiments presented values over the pre-established standard value (lower than 10\%), ${ }^{37}$ considering the peak 2 , probably due to low concentration of trifluralin in the electrochemical cell $\left(5.50 \times 10^{-7} \mathrm{~mol} \mathrm{~L}^{-1}\right)$. Besides, the redox reaction of trifluralin generates products that get strongly adsorbed under p-AgSAE and in sequentially experiments remain the p-AgSAE surface blocked, reducing the current signal and consequently the repeatability and reproducibility of the proposed methodology. However, the results obtained for peak 3 demonstrate that the methodology can provide adequate accuracy and precision in the analytical determination of trifluralin.

So, it can be observed that the use of $\mathrm{p}-\mathrm{AgSAE}$ combined with the SWV technique provided an alternative method for the analytical determination of trifluralin due to the possibility of its use in the simple and reliable determination in concentrations comparable with those obtained by HPLC/UV-Vis. These chromatography techniques involve the inconvenience of being expensive, require preparation, 
clean-up steps and preconcentration of the samples, and, most significantly, employ organic solvents, which can damage the environment. Besides, in this work it was shown that the use of $\mathrm{p}-\mathrm{AgSAE}$ provides a suitable alternative for the electrochemical determination of trifluralin, substituting HMDE that present the inconvenience of being highly toxic, or other solid electrodes that have the reproducibility damaged by adsorptive processes under electrodic surfaces or modified electrodes, they also can present excessive costs and difficult in surface reproducibility.

The calculated values for LOD, LOQ, the recovery efficiencies, repeatability and reproducibility are all suitable for use in the determination of low levels of trifluralin. So, the proposed methodology was used for its determination of residue levels in freshly food samples, such as grape and orange juice, plus eggplant, tomato and carrot samples.

\section{Application in fresh food samples}

The proposed methodology to trifluralin determination was employed in the analysis of fresh food samples. For this, $5.0 \mathrm{~g}$ of each sample was artificially contaminated by the addition of $1.00 \times 10^{-5} \mathrm{~mol} \mathrm{~L}^{-1}$ of trifluralin stock solution for grape and orange juices, tomato and carrot, whereas the eggplant samples were contaminated with
$7.70 \times 10^{-6} \mathrm{~mol} \mathrm{~L}^{-1}$ of trifluralin stock solution, which were called as fortified samples. These samples were prepared according to described in Experimental section, and $1 \mathrm{~mL}$ aliquot resulting solution was added to the electrochemical cell, and recovery curves were built using the standard addition method. The same methodology was effectuated in these samples, without any artificial contamination, which was called as no fortified samples, and this enabled verification of the methodology's efficiency of the analysis and preparation of the samples.

Recovery curves were performed in triplicate using all samples, fortified and no fortified, and the resultant voltammetric profile did not have great alterations concerning the $E_{p}$ values when compared with the experiments realized in the pure supporting electrolyte. The linearization of the recovery curves was performed similarly to effectuated in the supporting electrolyte and described above. The recovered concentration and recovery percentage values were calculated as described in Experimental section, and they are shown in Tables 2 and 3, for peaks 2 and 3, respectively.

Two juice samples had the presence of interfering compounds, which promoted a decrease in analytical signals without dislodgment in the signal of $E_{p}$ when compared to trifluralin responses in the electrolyte. These

Table 2. Recovery efficiencies for peak 2 from trifluralin determination in freshly food samples using p-AgSAE and SWV. Experiments performed in triplicate

\begin{tabular}{|c|c|c|c|c|c|}
\hline Sample & $\begin{array}{c}\text { Fortification / } \\
\left.(\mu \mathrm{mol} \mathrm{L})^{-1}\right)\end{array}$ & $\begin{array}{c}{[\text { Trifluralin }]_{\text {added }} /} \\
\left.(\mu \mathrm{mol} \mathrm{L})^{-1}\right)\end{array}$ & $\begin{array}{c}{[\text { Trifluralin }]_{\text {found }} /} \\
\left.(\mu \mathrm{mol} \mathrm{L})^{-1}\right)\end{array}$ & Recovery / \% & Bias / \% \\
\hline Carrot & 1.00 & - & 0.98 & 98.16 & -2.00 \\
\hline Carrot & - & 0.70 & 0.65 & 93.57 & -7.14 \\
\hline Tomato & - & 1.40 & 1.41 & 100.71 & +0.71 \\
\hline Eggplant & 0.70 & - & 0.69 & 98.38 & -1.43 \\
\hline Eggplant & - & 0.70 & 0.68 & 97.09 & -2.86 \\
\hline Grape & 1.00 & - & 0.97 & 97.06 & -3.00 \\
\hline Grape & - & 0.85 & 0.83 & 98.12 & -2.35 \\
\hline
\end{tabular}

Table 3. Recovery efficiencies for peak 3 from trifluralin determination in freshly food samples using p-AgSAE and SWV. Experiments performed in triplicate

\begin{tabular}{|c|c|c|c|c|c|}
\hline Sample & $\begin{array}{l}\text { Fortification / } \\
\left.(\mu \mathrm{mol} \mathrm{L})^{-1}\right)\end{array}$ & $\begin{array}{c}{[\text { Trifluralin }]_{\text {added }} /} \\
\left.\quad(\mu \mathrm{mol} \mathrm{L})^{-1}\right)\end{array}$ & $\begin{array}{l}{[\text { Trifluralin }]_{\text {found }} /} \\
\left.\quad(\mu \mathrm{mol} \mathrm{L})^{-1}\right)\end{array}$ & Recovery / \% & Bias / \% \\
\hline Carrot & 1.00 & - & 0.98 & 97.71 & -2.00 \\
\hline Carrot & - & 0.70 & 0.67 & 95.48 & -4.29 \\
\hline Tomato & 1.00 & - & 0.98 & 98.43 & -2.00 \\
\hline Tomato & - & 1.40 & 1.41 & 100.71 & +0.71 \\
\hline Eggplant & 0.70 & - & 0.68 & 97.81 & -2.86 \\
\hline Eggplant & - & 0.70 & 0.69 & 98.62 & -1.43 \\
\hline Orange & & 1.30 & 1.29 & 99.82 & -0.77 \\
\hline Grape & 1.00 & - & 0.92 & 92.45 & -8.00 \\
\hline Grape & - & 0.85 & 0.83 & 98.12 & -2.35 \\
\hline
\end{tabular}


interferences are probably due to the presence of phenolic compounds, organic acids and sugars, that also were extracted jointly with trifluralin by use of acetone solvent and interferes in the voltammetric responses of trifluralin. ${ }^{29}$ The presence of these interferences did not significantly affect the analysis of grape juice, being possible to obtain recovery efficiencies of 97 and $92 \%$ for the peaks 2 and 3, respectively. However, for orange juice sample fortified, the trifluralin response was damage by interference response in the same interval potential, indicating that probably occurred a strong interaction between trifluralin with some orange components.

The eggplant and carrot did not show displacement of the $\mathrm{E}_{\mathrm{p}}$ values when compared to trifluralin responses in $\mathrm{BR}$ buffer. Like observed in analytical curves in the electrolyte, the increase in trifluralin concentration promoted a dislodgment in $\mathrm{E}_{\mathrm{p}}$ values to more cathodic values in fortified eggplant sample as the inserts demonstrating the linearized recovery curves. However, for tomato sample occurred the presence of one peak around $-0.45 \mathrm{~V}$, due to dislodgment of peaks 2 and 3 of trifluralin to more cathodic values. Additionally, both trifluralin peaks increased with trifluralin addition, permitting, this way, the recovery percentages presented in Tables 2 and 3.

The accuracy of the recovery experiments in fresh food samples was evaluated using the Bias parameters, which statistically indicated the concordance between the added concentration and the recovered concentration, for fortified and no fortified samples. Therefore, the accuracy was calculated from the Bias parameter according to:

$\operatorname{Bias}(\%)=\frac{\bar{x}-x_{0}}{x_{0}} \times 100$

where $\overline{\mathrm{x}}$ is the average from recovered concentrations and $\mathrm{x}_{0}$ is the added concentration. ${ }^{38}$

Therefore, the calculated Bias were shown in Tables 2 and 3, and all samples presented values very satisfactory for analytical methodologies, indicating that the proposed methodology is robustness, because it presents a minimum interference in the SWV responses. So, the proposed methodology was simple and fast, presented low cost in the pre-treatment steps, was sensitive and mainly allowed the use of a nontoxic procedure to trifluralin determination in complex samples.

\section{Conclusions}

The experimental and voltammetric parameters were properly evaluated to the electroanalytical determination of trifluralin on $\mathrm{p}-\mathrm{AgSAE}$, and so, the best responses were obtained in $0.04 \mathrm{~mol} \mathrm{~L}^{-1} \mathrm{BR}$ buffer $\mathrm{pH} 7.0$, with $f=100 \mathrm{~s}^{-1}, \mathrm{a}=-50 \mathrm{mV}, \Delta \mathrm{E}_{\mathrm{s}}=-2 \mathrm{mV}, \mathrm{E}_{\mathrm{acc}}=-0.143 \mathrm{~V}$ and $\mathrm{t}_{\mathrm{acc}}=15 \mathrm{~s}$. Analysis in the electrolyte using the proposed methodology allowed a very low limit of detection of 1.53 and $1.39 \mu \mathrm{g} \mathrm{L}-1$, for peaks 2 and 3, respectively, with suitable precision values. The analytical sensibility is like results previously published using mercury electrodes and solid surfaces, such as HMDE and GCE electrodes, indicating that the proposed electroanalytical methodology is a reliable tool to the determination of trifluralin residues in small concentrations.

The application of the methodology described in this work in fresh food samples indicated that in complex samples was enabled to obtain the real concentration of trifluralin with good precision and accuracy. Besides this, the voltammetric had little influence from the variation in the composition of the sample, which indicates suitable robustness of the proposed methodology. Furthermore, this work demonstrated that the proposed methodology using p-AgSAE can be considered an environmentally friendly tool since it does not produce mercury or organic solvents residues, without toxic waste generation, according to green chemical statements.

\section{Acknowledgments}

The authors acknowledge the financial support from FAPEMIG (Fundação de Amparo à Pesquisa do Estado de Minas Gerais), process APQ-02704-17 and PROPP/UFU. D. Gonçalves Filho wishes to thank FAPEMIG for the scholarship. This work is a collaboration research project of members of the Rede Mineira de Química (RQ-MG).

\section{References}

1. Conti, C. L.; Barbosa,W. M.; Simão, J. B. P.; Álvares-da-Silva, A. M.; Psychiatry Res. 2018, 260, 187.

2. Winter, C. K.; Jara, E. A.; J. Integr. Agric. 2015, 14, 2358.

3. Kim, K. H.; Kabir, E.; Jahan, S. A.; Sci. Total Environ. 2017, $575,525$.

4. Saghir, S. A.; Charles, G. D.; Bartels, M. J. L.; Kan, H. L.; Dryzga, M. D.; Brzak, K. A.; Clark, A. J.; Toxicol. Lett. 2008, 180, 38.

5. Kılıç, Z. S.; Aydın, S.; Bucurgat; Ü. Ü.; Başaran, N.; Food Chem. Toxicol. 2018, 113, 90.

6. http://cues.cfans.umn.edu/old/pollinators/pdf-pesticides/ ForestServiceImidacloprid.pdf, accessed in March 2021.

7. Kovacic, P.; Somanathan, R.; J. Appl. Toxicol. 2014, 34, 810.

8. Kovacic, P.; Osuna Jr., J.; Curr. Pharm. Des. 2000, 6, 277.

9. Cabras, P.; Melis, M.; Spanedda, L.; Tuberoso, C.; J. Chromatogr. A 1991, 585, 164. 
10. Vitali, P.; Venturini, E.; Bonora, C.; Calori, R.; Raffaelli, R.; J. Chromatogr. A 1994, 660, 219.

11. Tong, C.; Guo, Y.; Liu, W.; Chemosphere 2010, 81, 430.

12. García-Valcárcel, A. I.; Sánchez-Brunete, C.; Martínez, L.; Tadeo, J. L.; J. Chromatogr. A 1996, 719, 113

13. Gajdár, J.; Barek, J.; Fischer, J.; J. Electroanal. Chem. 2016, $778,1$.

14. Wen, X.; Fei, J.; Chen, X.; Yi, L.; Ge, F.; Huang, M.; Environ. Pollut. 2008, 156, 1015.

15. Kotouček, M.; Opravilová, M.; Anal. Chim. Acta 1996, 329, 73.

16. Ferro, E. C.; Cardoso, C. A. L.; Arruda, G. J.; J. Environ. Sci. Health, Part B 2017, 10, 762.

17. Gonçalves-Filho, D.; Silva, C. C. G.; de Souza, D.; Talanta 2020, 212, 120756.

18. Barek, J.; Fischer, J.; Navratil, T.; Peckova, K.; Yosypchuk, B.; Sensors 2006, 6, 445.

19. Yosypchuk, B.; Navratil, T.; Lukina, A. N.; Peckova, K.; Barek, J.; Chem. Anal. 2007, 52, 897.

20. Vyskocil, V.; Navratil, T.; Danhel, A.; Dedik, J.; Krejcova, Z.; Skvorova, L.; Tvrdikova, J.; Barek, J.; Electroanalysis 2011, $23,129$.

21. Danhel, A.; Barek, J.; Curr. Org. Chem. 2011, 15, 2957.

22. Yosypchuk, B.; Barek, J.; Crit. Rev. Anal. Chem. 2009, 39, 189.

23. Fischer, J.; Vanourkova, L.; Danhel, A.; Vyskocil, V.; Cizek, K.; Barek, J.; Peckova, K.; Yosypchuk, B.; Navratil, T.; Int. J. Electrochem. Sci. 2007, 2, 226.

24. Yosypchuk, B.; Fojta, M.; Barek, J.; Electroanalysis 2010, 22, 1967.

25. Britton, H. T. S.; Robinson, A. R.; J. Chem. Soc. 1931, 1456.

26. de Souza, D.; Mascaro, L. H.; Fatibello-Filho, O.; J. Solid State Electrochem. 2011, 15, 2023.
27. Mocak, J.; Bond, A. M.; Mitchell, S.; Scollary, G.; Pure Appl. Chem. 1997, 69, 297.

28. Analytical Methods Committee; Analyst 1987, 112, 199.

29. Thriveni, T.; Rajesh Kumar, J.; Sujatha, D.; Sreedhar, N. Y.; Food Chem. 2007, 104, 1304.

30. Mirčeski, V.; Lovrić, M.; Komorsky-Lovrić, S.; Square-Wave Voltammetry: Theory and Application; Springer: Berlin, 2007.

31. Giles, C. H.; Smith, D.; Huitson, A.; J. Colloid Interface Sci. 1974, 47, 755 .

32. Giles, C. H.; D'Silva, A. P.; Easton, I. A.; J. Colloid Interface Sci. 1974, 47, 766

33. Kudryashov, N. A.; Appl. Math. Comput. 2008, 205, 396.

34. Kudryashov, N. A; Loguinova, N. B.; Appl. Math. Comput. 2010, 217, 3575

35. Silva, L. M.; de Souza, D.; Electrochim. Acta 2017, 224, 541.

36. United States Environmental Protection Agency (EPA); Reregistration Eligibility Decision Bromoxynil; Office of Prevention, Pesticides and Toxic Substances: Washington D.C., 1998, available at https://www3.epa.gov/pesticides/endanger/ litstatus/effects/bromoxynil/attac1-red.pdf, accessed in March 2021.

37. Skoog, D. A.; West, D. M.; Holler, F. J.; Crouch, S. R.; Fundamentals of Analytical Chemistry, $9^{\text {th }}$ ed.; ThomsonBrooks: New York, 2014.

38. Miller, J. N.; Miller, J. C.; Statistics and Chemometrics for Analytical Chemistry; Pearson/Prentice Hall: Bristol, United Kingdom, 2005.

Submitted: October 19, 2020

Published online: April 5, 2021 